generally accepted theory of aetiology. Most of my cases appeared to be infective in origin, and two of them followed instrumentation. It does appear that the disease is associated with poor hygiene. Fournier's gangrene was fairly common in Europe and North America at the turn of the century but is now rarely reported from these areas. More recent reports of more than one case have come from areas with poor living standards. ${ }^{4-6}$

It was suggested that the patient described may have had an increased tendency to vascular insufficiency because of a high titre of cold haemagglutinins in his serum. It is possible that this and the trauma he suffered were enough to precipitate gangrene of the scrotum by vascular thrombosis. Several au'hors have proposed that the cause of Fournier's gangrene is an arterial thrombosis precipitated by an infection, analogous to cavernous sinus thrombosis. ${ }^{6-8}$ This case could be compatible with the thrombosis theory of aetiology.-I am, etc.,

P.A. Central Hospital,

Douglas J. Buchanan

Ndola, Zambia

1 Buchanan, D. J., Medical fournal of Zambia, 2 Allen, J., Fournal of Cutaneous and GenitoUrinary Diseases, 1894, 12, 55 .

3 Randall, A., Ұournal of Urology, 1920, 4, 219. $19,3,25,60$. 19J3, 25, 60. J., South African Medical fournal,
1951, 25, 222.

Sachdeva, Y. V., and Khanna, B. C., Indian Fournal of Surgery, 1949, 11, 178

Carver, J., British Fournal of Urology, 1939,

Mansfield, O. T., British fournal of Surgery, $1946,33,275$.

\section{Asthma in the Elderly}

SIR,-May I briefly comment on two points in the paper by Drs. $H$. Y. Lee and $T$. B. Stretton (14 October, p. 93)?

Reversible obstruction of the airways occurs very often in both young and elderly patients suffering from chronic non-specific lung disease. The attacks, especially when repeated, are mostly accompanied by signs of alveolar hypoventilation. I feel that the 15 elderly patients studied by the authors fufilled only partly the criteria for the diagnosis of asthma-no hypercapnia and no reversibility of obstruction were found in most of them. Diminished vital capacity may indicate a restrictive ventilatory disturbance. I wonder if measurement of the $\mathrm{FEV}_{1}$ alone is suitable for the diagnosis of obstruction; if the residual volume is increased, a low $\mathrm{FEV}_{1}$ may simply result from high intrathoracic pressure during expiration. Now that body plethysmography is available, assessment of the residual volume and/or intrathoracic gas volume has become very simple, and the resistance of the smaller airways during normal expiration may also be calculated. I suggest therefore that the term "asthma" should be reserved for those cases in which reversible airways obstruction is quite clearly demonstrable and that it should not be used simply as a symptomatic label.

I also disagree with another statement of the authors concerning sputum eosinophilia. Our findings in more than 15,000 samples of bronchial secretion prepared from sputum by Mulder's technique during the past eight years have shown that eosinophilia is a very common consequence of bronchial hyperreactivity. Moreover, a longterm follow-up study in Europe's first model village for the treatment of chronic nonspecific lung disease in Zákànyszèk, South Hungary, showed bronchial eosinophilia to be fairly constant in the greater part of a total of 384 patients, only a few of whom ever had real obstructive attacks. Eosinophilia correlates closely with bacterial infection of the bronchi and may serve as a basic indicator in the assessment of airway infections, ${ }^{12}$ as active bronchial infection causes the eosinophils to disappear. Since the main physiological role attributed to eosinophils is the local release of histamine and since immune reactions of type I (reaginic type) often cause the production of eosinophil chemotactic factor, ${ }^{3}$ bronchial eosinophilia seems to be a very complex phenomenon. It is surely oversimplifying the position to say that "sputum eosinophilia is of considerable value in assessing asthmatic patients." It may be of value and it may not.-I am, etc.,

Department of Pneumology,

Miklos LaNYI Semmelweis University, Budapest

1 Lányi, M., Lancet, 1967, 1, 1165

2 Lányi, M., Deutsche Medizinische Wochenschrift, 3 Kay, A. B3, 2390 . Stechschulte, D. J., and Austen, K. F., fournal of Allergy, 197i, 47, 118.

SIR-I read with interest the article on this subject by Drs. H. Y. Lee and T. B. Stretton (14 October, p. 93). I am rather concerned, however, about the suggested treatment. While systemic corticosteroids are essential and life-saving at times their constant use has created over the past 10 years the problem of corticosteroid-dependent asthma. In my unit we have been trying over the past 18 months to treat these patients with initial doses of systemic corticosteroid followed by aerosol inhalants of beclomethasone. This is a synthetic, poorly-absorbing corticosteroid, and we have used it successfully in 82 out of 95 cases of late-onset asthma. These have been followed up for 12 months, and we hope to publish the results.-I am, etc.,

\section{S. S. Chatterjee}

Department of Respiratory Physiology, Baguley Hospital, Baguley Hos
Manchester

\section{Bicarbonate Solutions for Infusion}

SIR,-It has come to our attention that $1.4 \%$ sodium bicarbonate infusion solutions are no longer available commercially in the U.K. and that the lowest concentrations being produced regularly are $2.74 \%$ (Polyfusor-Boots) and $4 \cdot 2 \%$ (Travenol Laboratories-Baxter). These firms may produce $1.4 \%$ sodium bicarbonate as a special order but this often takes several months. It is therefore important that all hospitals which may at some time or another admit acutely poisoned patients should review their procedures for forced alkaline diuresis, as many of these regimens include $1.4 \%$ sodium bicarbonate solution.

Sodium bicarbonate solutions are used in forced alkaline diuresis regimens to promote the alkalinization of the urine and therefore it might appear that any procedure would be adequate which adjusts the proportion of sodium bicarbonate to the total infusion volume to give a urinary $\mathrm{pH}$ of 8 . (The $\mathrm{pH}$ indicator portion of Bililabstix is not suitable, in our experience, for this purpose and, if a $\mathrm{pH}$ meter is not available, narrow-range indicator paper should be used.) However, owing to the length of time required for the renal compensation of acid/base disturbances, the patient may become more alkalaemic than hitherto before producing a significantly alkaline urine if these more concentrated solutions are used. In our experience there may be a transient rise in the blood levels of phenobarbitone when the phenobarbitone-poisoned patient first develops a base excess, and we are concerned that this rise may be considerably higher if the rate of infusion of alkali in a forced alkaline diuresis regimen is increased at any time. It would appear to us that one method which would overcome this difficulty is to give the sodium bicarbonate simultaneously with other infusion fluids connected with a Y-piece, but we would be interested to hear what other cintres are planning to do.-We are, etc.,

E. SIMPSON M. J. STEWART Patricia GoOdHEad

Department of Clinical Chemistry,

Muryfield

Normal Range of "Effective Thyroxine Ratio"

SIR,-Standardized reagent kits for measurement of the "effective thyroxine ratio" (E.T.R.) have become avaulable relat.v.ly recently (Mallinckrodt U.K. Ltd.). This test has been shown ${ }^{12}$ to have a diagnostic accuracy comparable to that of a free thyroxine index in categorizing patients according to their thyroid status. Since the tentative normal range $(0 \cdot 86-1 \cdot 13)$ published by the manufacturers was based upon a population of wide geographical distribution, users were recommended to establish their own normal values. Having used this test routinely in our biochemistry department for some months, we have now analysed our first 1,000 results with this object in view, and present our findings here for the interest of other current or potential users.

We used the reagent kits according to the manufacturers' instructions, except that a pool of at least 50 human sera taken from routine samples was used as a standard instead of the lyophilized material supplied; this modification was found to improve the precision of the assay (from S.D. $=0.032$ to S.D. $=0.019$ within batch)

The results, plotted on probability paper according to Hoffmann ${ }^{3}$ are shown in the Figure, where it can be seen that the cumulative percentage incidence of the values found is linear between approximately 10 to $85 \%$. It seems reasonable to assume that this range of intermediate values, containing some $75 \%$ of all the results, is derived from euthyroid subjects and that, since the linearity of the graph in this region indicates a Gaussian distribution, the range of E.T.R. values for $95 \%$ of euthyroid subjects may be obtained by extrapolation of this straight line as suggested by Hoffmann. ${ }^{3}$ The range thus found is $0.88-1 \cdot 09$. This is similar to that found by Thorson et al. ${ }^{1}$ in 198 normal subjects (0.89-1.09), but broader than that found by Murray et al. ${ }^{2}$ in 80 such subjects $(0.89$ 1.05). The latter authors suggested the existence of "borderline" zones between 0.86 and 0.89 and between 1.06 and 1.09; this is consistent with our own findings, as shown in the Figure, where deviation from 
linearity below 0.90 and above 1.05 suggests some overlap between euthyroid E.T.R. values and hypo- or hyperthyroid results.

The E.T.R. results from 25 pregnant women and 14 women who were taking oestrogen-containing contraceptive preparations were 0.91-1.04 and 0.93-1.06 respectively.

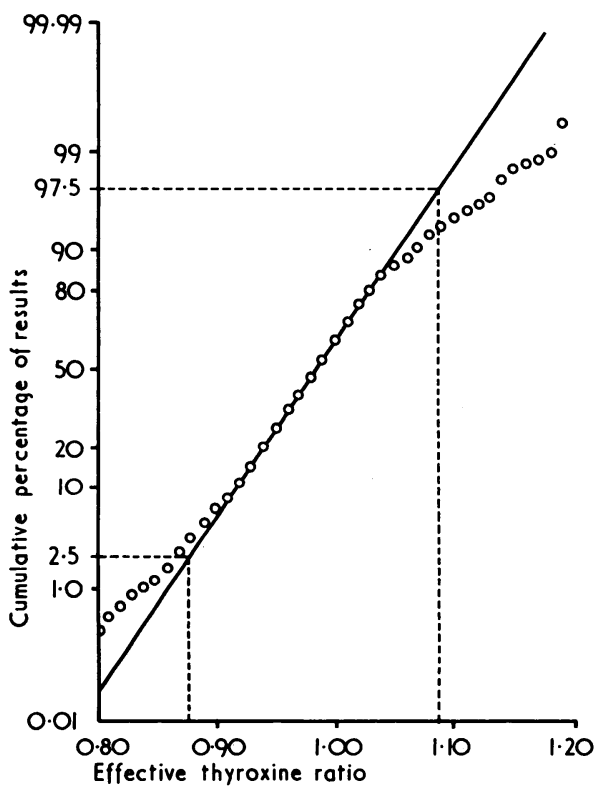

In limited series in which patients were classified by clinical diagnostic indices or by measurement of radioactive iodine uptake by the thyroid the results of E.T.R. measurement have correlated well with these other parameters, on the basis of the normal range proposed. It is hoped to publish details of these investigations at a later date.-We are, etc.,

M. G. WELLS

P. R. WIKRAMANAYAKE J. W. WOOLLEN

Edgware General Hospital,

Edgware, Middlesex

1 Thorson, S. C., Mincey, E. K., McIntosh, H. W and Morriso.

2 Murray, I. $\mathbf{P}$. C., Parkin, J., and Gubanyi, M. Medical Fournal of Australia, 1972, $1,1190$.

Hoffmann, R. G.; fournal of the
Medical Association, 1963, 185, 864.

\section{Little Red Book from the} Park of Cathay

SiR,-Your cosy leading article on the plan to reorganize our health services in Wales (14 October, p. 61) aroused no comment except from an emigré in England rejoicing quite rightly that some of your words were in Welsh. Do not therefore imagine that all is seen to be well. In Pembrokeshire, for instance, a demoralizing dismembering of the hospital started by the Welsh Hospital Board will be completed by the Welsh Office, because it is argued that the social needs of people must now yield to the administrator's drive towards local authority reform.

A new hospital long since promised for Pembrokeshire-to replace a frail old thing sustained by faith, hope, and creosote-if ever built will be too small. There is now a paediatric ward, but in the future, by some incredibly foolish reasoning, most children in need of treatment will be removed 30 miles and more, and all other overflow patients with cardiac infarction, perforated viscera, and broken bones will be subjected to the same indignity. Already it is proving more efficient for many of our elderly to go far from home, like elephants, to die.

When ministers of government, civil servants, hospital boards, and their administrators harm their fellow creatures guilt is somehow lessened in the sharing and the equanimity survives. Or is it that they know not what they do? But in a truly enlightened Christian society when a whole community and its worried nurses and doctors lose faith in an administration surely there should be access to another, unbiased, court of appeal. The little red book does not say so.-I am, etc.

EIrIaN WiLliams

Pembroke County War Memorial Hospital, Haverfordwest

\section{Chambers "In Principle"}

SIR,-Congratulations, Sir Paul! As one of those who felt buoyant after the S.R.M. went over into the Chambers era but who felt unable to give the overall rubber stamp, because (as with guarantees and hire purchase agreements) of the "small print," I would like before it is too late to discuss the "small print." There was no opportunity in the debate to bring out some vital factors. In Section V, paragraph 6 of his report ${ }^{1}$ Sir Paul advocates the excellent general principle that small committees "should analyse and discuss in depth particular subjects ...." Where I have misgivings is with the rest of the sentence, which speaks of approval and executive action by a central executive only, lest action be frustrated by reference to the Representative Body.

Some of the major blunders and inadequacies of N.H.S. planning arise precisely from the omniscience of central planners who do not adequately consult others outside their charmed circles. True, these circles are obviously made up of bright, knowledgcable people, and those they consult outside similarly bright. However, it would not he a surprise if they happened to choose people with rather similar views and experience to consult with. Thus, because of the rousin cry for strength and simplicity, the country is irrevocably saddled with physical structures and systems which, had these powerful men given experienced people actually in the field a chance to comment, might have been much better structures and systems from the start. One of the big complaints about the B.M.A. has been detachment from those in the field. Some of the new proposals, far from meeting this, will make it worse, with predictably bad consequences.

In regard to B.M.A organization, the present system, where powerful members of central executive bodies are elected by people who really know them, works well. It means that their performance and activities are monitored by colleagues in the field. It also means that there is genuine feeback from those having to treat patien's, particularly outside London. There is no substitute for personal contact of this kind. To rely on people happening to see reports in the B.M.F. or seeing their elected member once a year is to ask for the inflation of the worst defects of the past.

The new proposals are that instead of local medical committees and regional hospital committees electing these people and seeing them regularly, they will be elected at the annual or bi-annual jamboree. Some of the people liable to be elected will not really be known to those who elect them and will never personally meet them. Qualities of speech-making and quick wit are excellent but may lead to other imbalances in representation. Elections in this atmosphere are more like those of the American President or British general elections with their manoeuvres and emotions.-I am, etc.,

Severalls Hospital,

HARRY JACOBS

Colchester, Hospital,

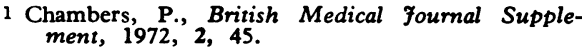

\section{New Consultant Contract}

SIR,-It was a pleasure to read Dr. J. W. Paulley's letter (18 November, p. 432). I would agree fully with his statement that the

B.M.A. have made a serious error of judgement in supporting junior hospital doctors' claims to the extent that we now have a system of overtime payments in use necessitating a consultant's signature. There is something degrading in the idea of the medical profession having a system of overtime payments, and it is obvious that we are well on the road to becoming another trade union.

As a provincial consultant who has worked in a small hospital for many years without adequate junior staff, I would like to support fully Dr. Paulley's statement that if a provincial hospital cannot be staffed properly, it should cease to be a consultant hospiral. If, for geographical reasons, it is necessary to keep a consultant service in a certain area, then it is up to the authority or regional board concerned to see that this hospital is adequately staffed. If this was done no consultant should object to having on-call responsibility for prolonged periods, and I cannot see that the proposed new consultant contract has any advantages whatever to offer. It is clearly introducing the principle of overtime pay, and this must be resisted by all consultants who have any regard whatever for the dignity of the medical profession.

No doubt we provincial consultants will get an opportunity at some time of voicing our disapproval of this proposed new contract, but to date no adequate account seems to have been taken of our views.-I am, etc.

Patrick J. SWeeney

Erne Hospital,
Enniskillen, Co. Fermanagh

\section{"Family Practitioner Committees"}

SIR,-I would like to support the suggestion from the members of the Berkshire Local Medical Committee (2 December, p. 554) that the present executive councils should be renamed general practitioners' committees, rather than family practitioner committees. I remember Dr. John Hunt, who was largely resvonsible for the foundation of the now Royal College of General Practitioners, saving that whatever else general practitioners are, they are general, and they are practitioners.-I am, etc.,

E. M. RosSER Secretary,

London S.W.1 